\title{
$\mathrm{PH} 9 \mathbf{9 7}$ acualiad
}

\section{El Año Murillo, un diálogo del Barroco con el s. XXI}

La celebración del IV Centenario del nacimiento de Bartolomé Esteban Murillo ha sido uno de los grandes acontecimientos que ha organizado la ciudad de Sevilla. Desde finales de noviembre de 2017 hasta marzo de 2019 se ha desarrollado un amplio programa de actividades de todas las disciplinas artísticas para redescubrir la figura de Murillo, genio indiscutible de la pintura barroca. La estrecha colaboración de instituciones públicas y privadas, del sector profesional de la cultura, la alianza estratégica con turismo, el esfuerzo de comunicación por crear una imagen de marca y la alta participación de los sevillanos y los visitantes, ha hecho posible crear un evento de ciudad de gran éxito. Una conmemoración que ha saltado fronteras y que ha puesto a Sevilla en el mapa internacional.

Isabel Ojeda Cruz | Ayuntamiento de Sevilla

URL de la contribución <http://www.iaph.es/revistaph/index.php/revistaph/article/view/4373>

El pasado 19 de marzo de 2019 se clausuró la celebración del 400 aniversario del nacimiento de Bartolomé Esteban Murillo, una efeméride que se inició el 28 de noviembre de 2017 con la exposición Murillo y los Capuchinos de Sevilla. Reconstrucción, en el Museo de Bellas Artes de la ciudad. Más de doce meses de Año Murillo, de noviembre de 2017 a marzo de 2019, ha sido el marco temporal para redescubrir, en toda su complejidad, la figura de uno de los artistas barrocos más importantes del mundo.

La organización de este evento surge de la voluntad del Ayuntamiento de Sevilla, que actuó como motor, pero desde el principio se concibió como un evento de ciudad capaz de reunir la iniciativa de las instituciones públicas (Consejería de Cultura, Universidades, Ministerio de Cultura, Catedral y Arzobispado, Reales Academias de las Artes y las Letras) y las capacidades de las privadas. El sector empresarial turístico y cultural de la ciudad se sumó desde el primer momento, aportando una increíble oferta que abarcaba todos los ámbitos (artes escénicas, musicales, rutas guiadas, gastronomía barroca, exposiciones, etc.). El Año Murillo se articuló como un gran paraguas, una marca que recogía y armonizaba todo el conjunto de actividades en torno al artista, pero siempre bajo la exigencia de la calidad y la excelencia.

Se constituyó una comisión científica, formada por catedráticos de arte expertos en Murillo pero también por personas destacadas en otros ámbitos estéticos y cultu-

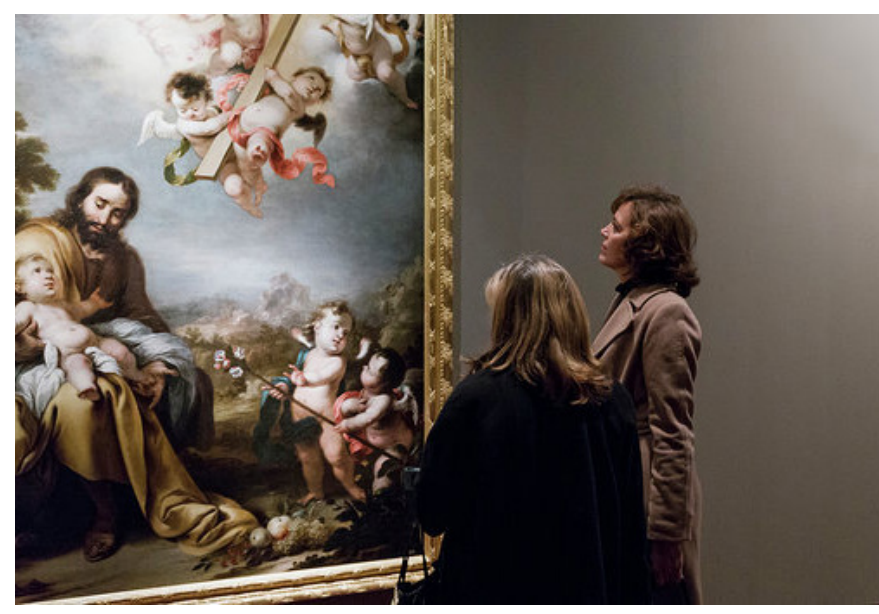

Exposición Murillo y su estela. Espacio Santa Clara | foto todas las imágenes son del Ayuntamiento de Sevilla

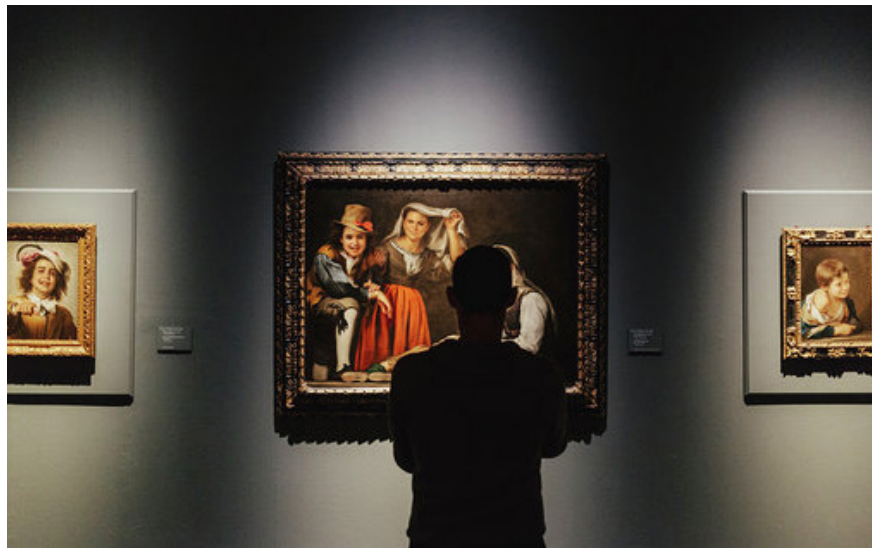

Exposición Murillo. IV Centenario. Museo de Bellas Artes de Sevilla 


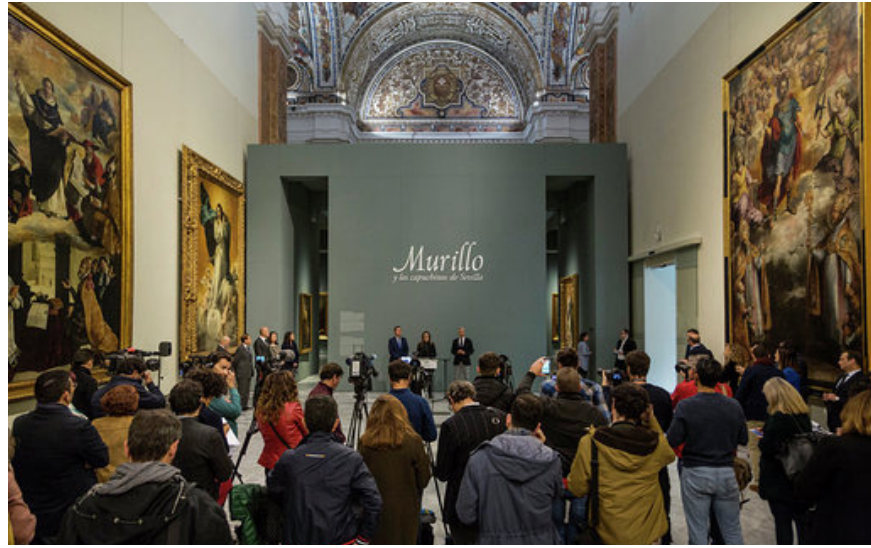

Presentación Institucional Año Murillo

rales que pudieran relacionar al artista con el siglo XXI. Se marcaron unos objetivos claros, entre los que cabría destacar el redescubrimiento del artista desde una visión poliédrica a fin de que su pintura-desde la devocional a la profana- llegara a ser entendida en su plenitud; la generación de nuevas rutas patrimoniales en la ciudad, iluminando los espacios Murillo, que albergan de forma permanente sus obras o que están ligados a su historia de algún modo; el desarrollo de líneas de investigación a través de publicaciones, congresos y trabajos de restauración (como el realizado por el IAPH para las dos obras maestras, Moisés haciendo brotar el agua de la roca de Horeb y el Milagro de la multiplicación de los panes y los peces realizados para la Caridad de Sevilla) de manera que la efeméride dejara huella. Y por último, un elemento clave: el Año Murillo no podía quedarse encerrado en la Sevilla barroca, tenía que dialogar con el presente, buscando la mirada innovadora que supuso Murillo en el siglo XVII y en la actualidad, descubriendo los Murillos del s. XXI. Empezamos en el Barroco y terminamos en la contemporaneidad. El Año Murillo ha reunido lo mejor de los maestros del Barroco y su estela, pero también obras de Beuys, Picasso, Paula Rego o Val del Omar. Las mejores expresiones del Barroco han convivido con propuestas insólitas, vanguardistas e inesperadas.

El programa se articuló en torno a un importante bloque expositivo en el Museo de Bellas Artes, el Espacio Santa Clara, la Catedral de Sevilla, el Archivo de Indias y el Archivo Municipal, Hospital de la Caridad, Cerámicas Triana y Facultad de Bellas Artes. Estos espacios alber-

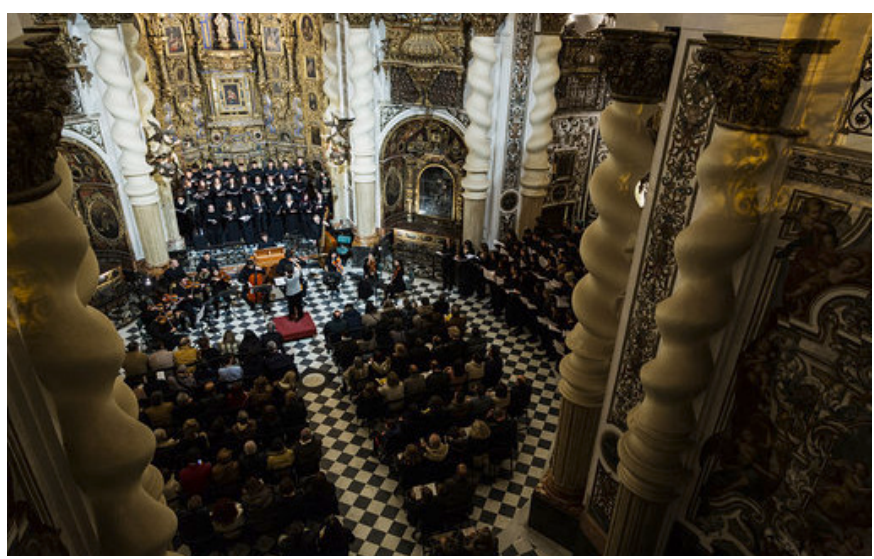

Concierto del ciclo La Europa de Murillo. San Luis de los Franceses

garon un total de trece exposiciones de diferentes temáticas y enfoques (loza, documentos, arte barroco, contemporáneo, fotografía...). Las cifras de visitantes batieron todos los récords: Murillo y su estela en Sevilla fue la exposición más visitada en el Espacio Santa Clara; Murillo. IV Centenario, la más vista en la historia del Museo de Bellas Artes; sin olvidar Murillo en la Catedral de Sevilla, que superó los 2 millones de visitas.

También se desarrolló un completo itinerario murillesco por toda la ciudad formado por veinte espacios públicos y privados que tenía como punto de partida la Casa Murillo (con más de 100.000 visitas), dedicada a la obra del autor y donde se repartían pasaportes para ir sellando en cada uno de los puntos indicados.

El Año Murillo se fue adaptando a las estaciones, y en primavera y en verano, la celebración se trasladó a la calle y a espacios patrimoniales emblemáticos como la Casa de la Moneda (Tras las huellas de Murillo), el Real Alcázar (visitas teatralizadas) o el Convento Nuestra Señora de los Reyes (Gratia Plena), con actuaciones musicales, autos sacramentales, danza o vídeomapping. Todos los lenguajes artísticos reinterpretaban al artista del Barroco.

Otro elemento clave en el desarrollo de esta efeméride fue la atención prestada a las actividades divulgativas y educativas. El Año Murillo ha sido una fiesta de todos para todos. Las exposiciones llegaron a todos los públicos (familias, niños) y también, a través de un acuerdo de colaboración con Autismo Sevilla y con la Fundación 


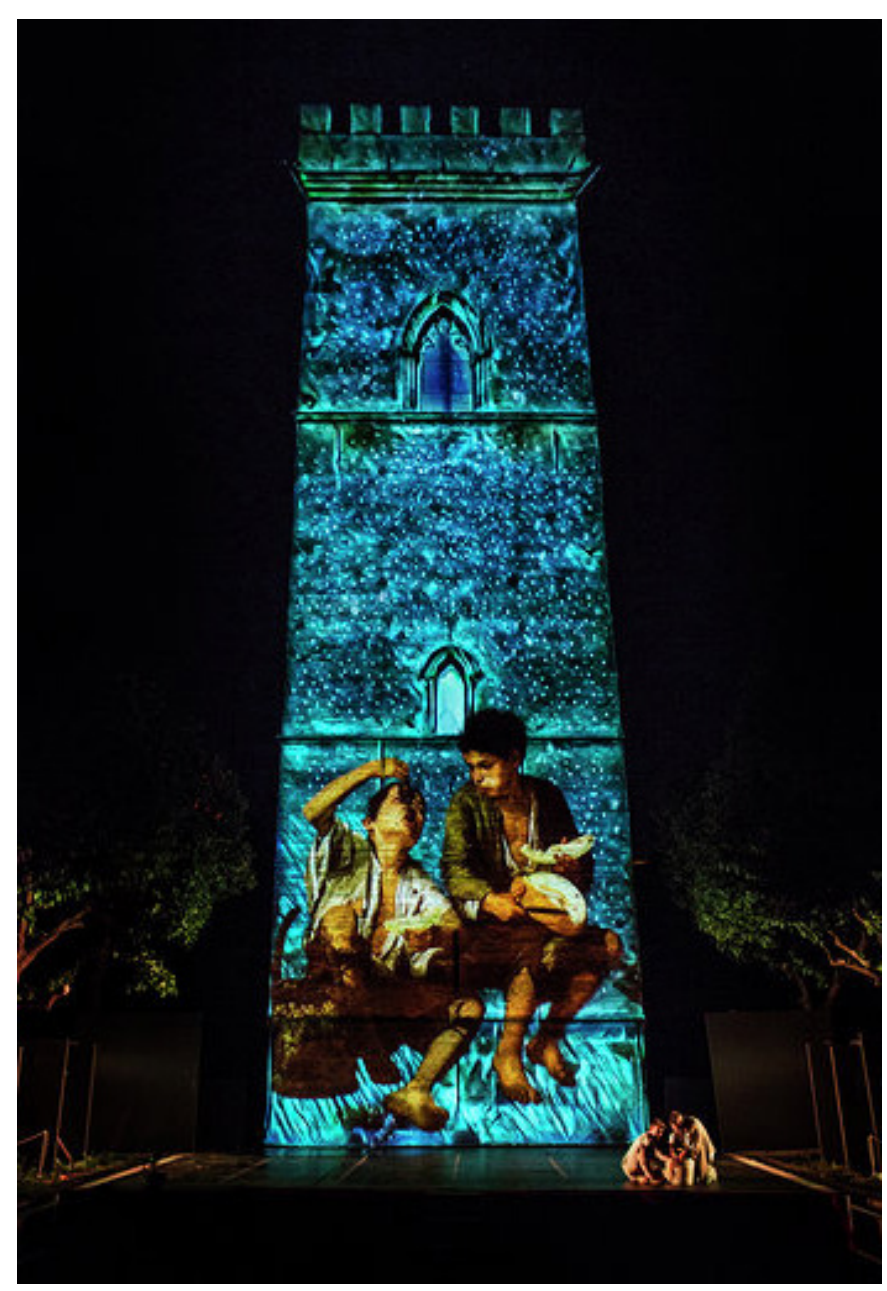

Espectáculo de vídeomapping y danza, Los niños de Murillo de Producciones Imperdibles. Torre de Don Fadrique

ONCE, se adaptaron los contenidos a lectura fácil y a personas con dificultades visuales. Además se organizó un amplio número de talleres en Casa Murillo, Museo de Bellas Artes y Espacio Santa Clara, sobre diversos aspectos como la transformación del color en las obras, técnicas de restauración o laboratorios de fotografías, collages y performances. El Año Murillo no sólo mostró las obras del artista, también fue una invitación a viajar en el tiempo y conocer de cerca su época, la Sevilla barroca que tan presente sigue hoy día. La literatura también se convirtió en un paseo, en las rutas organizadas por Eva Díaz Pérez para recorrer los lugares mencionados en su novela sobre Murillo: El Color de los Ángeles.
La efeméride tenía que impregnar la vida de la ciudad, pero también debía ser todo un referente a nivel de investigación. El trabajo realizado por el profesor Benito Navarrete con la organización del Congreso Internacional: Murillo ante su centenario. Perspectivas historiográficas y culturales reunió en Sevilla a cincuenta ponentes internacionales y más de cien inscritos participaron en la redefinición de Murillo. También la exposición Aplicación Murillo: Materialismo, Charitas y Populismos, comisariada por Pedro G. Romero, Luis Martínez Montiel y Joaquín Vázquez, ayudó a relanzar la figura del genio desde la contemporaneidad, tras haber sido denostada por las vanguardias históricas. Esta exposición ha sido un gran ejercicio de investigación (más de quinientas obras repartidas en cinco sedes expositivas), no en vano le valió la mención por la prensa especializada de mejor exposición de 2018.

A este bloque habría que sumar la decena de publicaciones que se han editado con motivo de la conmemoración, libros que sin duda marcan un antes y un después en el conocimiento de Murillo.

La celebración del IV Centenario del Nacimiento de Murillo ha vuelto a demostrar la capacidad que tiene la ciudad de Sevilla para celebrar con éxito eventos de grandes dimensiones con repercusión internacional. El trabajo conjunto del sector público y privado y de la cultura y el turismo lo ha hecho posible. Hemos reforzado la idea de que nuestra cultura y nuestro patrimonio son dos de los grandes activos que tiene la ciudad. Murillo consiguió aupar a Sevilla como mejor destino turístico 2018 según Lonely Planet y New York Times. Más de 3 millones de visitantes han participado en un programa de actividades sin precedentes confirmando la madurez cultural de la ciudad. Además el IV Centenario se queda en Sevilla de múltiples formas, porque el pintor y la ciudad son inseparables; queda la Casa Murillo, quedan las rutas patrimoniales y la pasión sevillana, en su concepción barroca, una de las principales señas de identidad de la ciudad. 